\title{
Pulmonary health status of ginning factory women laborers in Tirupur, India
}

\begin{abstract}
Ginning factories discharge large amounts of cotton dust, which leads to decreased pulmonary function in the exposed subjects. An attempt was made to study the pulmonary functions of women laborers employed in ginning factory located in Tirupur, a textile based city in Coimbatore district of Tamilnadu, India. The women were subjected to spirometric analysis and chest X-ray examinations. Occupational lung disorders that included byssinosis, chronic bronchitis and occupational asthma were studied in these women by assessing their pulmonary function tests, clinical symptoms, age and duration of exposure to cotton dust. Standard normal distribution, Chi-square analysis and multiple correlation analysis were the statistical methods applied in this study. Significant occupational acute and chronic pulmonary changes were observed in these women. Both age and duration of exposure together had a significant impact on their pulmonary function as per the results of the multiple correlation statistical analysis. There was a significant distribution of women with pulmonary impairment in all the sections of the ginning factory. Some recommendations were also suggested for controlling the occupational lung diseases caused by cotton dust.
\end{abstract}

Key words: Byssinosis, ginning process, pulmonary function tests, spirometry

\section{INTRODUCTION}

Byssinosis and other related respiratory abnormalities are well-known occupational respiratory diseases in textile mill workers caused by cotton dust pollution. ${ }^{[1]}$ Cotton ginning and pressing have been identified as traditional industries under the unorganized sector which functions on a seasonal basis. The employees in ginning factories do not get registered under the Employees Security Insurance act. Till date in India, only a limited number of studies have been conducted to highlight the occupational hazards in ginning factories and there are hardly any studies conducted on the employees of ginning factories in Coimbatore district, Tamilnadu. Tirupur being a textile city in Coimbatore district, is the major exporter in cotton garments and ranks second to Coimbatore city where 18 ginning factories are situated employing 1500 laborers. Women are the major employees in these ginning factories.
Although the textile industry in India has a large population for many years, health hazards in the women laborers in these ginning factories have been overlooked. Moreover all the studies conducted so far, were in late 1980s and there is no recent study, which portrays clearly the health status of ginning workers especially in Tirupur. Working women have multiple roles to play as a wife, a mother and an employee. Being subject to dual demands of home and workplace, they are liable to face crisis of adjustment which may cause stress and strain. ${ }^{[2]}$ The present study was therefore undertaken to assess the pulmonary function of women laborers in a selected ginning factory at Tirupur.

\section{MATERIALS AND METHODS}

\section{Selection of subjects}

A ginning factory located at Tirupur was chosen for the study. 104 women laborers working in different sections of the selected ginning factory namely the sorting house, gin house and gutter formed the experimental group. Sorting involves the sorting of cotton according to quality. The seeds are separated from cotton in the gin house and collected in the gutter. Among the 104 women laborers, 56 were employed in the gin house section, 38 in the gutter and 10 in the sorting section. Working hours of these workers were from $8 \mathrm{am}$ to $5 \mathrm{pm}$ for all week days during seasonal times, without using any self-protective measures. These women were grouped based on their age and working experience [Table 1].

\section{Assessment of pulmonary health \\ A questionnaire (based on the British}

J. V. Jannet, G. P. Jeyanthi* Department of Bioinformatics, School of Biotechnology, Karunya Deemed University, Coimbatore - 641 114, Tamilnadu; *Department of Biochemistry, Avinashilingam Deemed University, Coimbatore - 641043 , Tamilnadu, India

For correspondence: Dr. Jannet J. V., School of Biotechnology, Karunya Deemed University, Coimbatore - 641114 , Tamilnadu, India. E-mail: jannet_r@karunya.edu

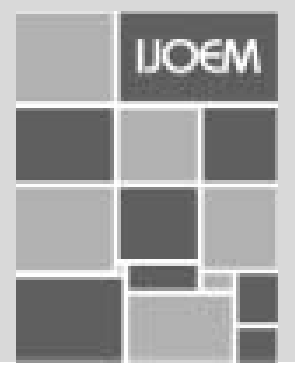


Table 1: Grouping of ginning factory women laborers

\begin{tabular}{lccc}
\hline Working & \multicolumn{2}{c}{ Age (years) } & Total \\
\cline { 2 - 3 } experience (years) & Below $\mathbf{5 0}$ & Above $\mathbf{5 0}$ & \\
\hline $0-9(41)$ & 20 & 21 & 41 \\
$10-19(18)$ & 8 & 10 & 18 \\
20 and above (45) & 16 & 29 & 45 \\
TOTAL (104) & 44 & 60 & 104 \\
\hline
\end{tabular}

Medical Research Council recommendation and modified for the use in India) was used to collect information regarding their name, age, economic background, work-experience in the present occupation, anthropometric measurements, clinical conditions and dietary habits. Forty age and sex matched control women of similar economic status were selected for the study. Physical examination of respiratory health of workers and control group were conducted in accordance with recommendations outlined in the declaration of Helsinki.

Four types of clinical symptomatic conditions were taken in to account to view the health conditions of ginning factory women laborers. They included byssinosis, chronic bronchitis, asthma and other ailments.

Byssinosis is a condition observed in cotton dust exposed worker. ${ }^{[3]}$ Byssinosis is an asthma-like condition in cotton workers worse at the beginning of the working week and most severe on returning to work after a longer period away from works. Therefore byssinosis is also ascribed as "Monday morning syndrome". The byssinotics in the selected ginning factory were graded according to their degrees of clinical symptoms suggested by Schilling. ${ }^{[4]}$ Grade $1 / 2$ - Occasional tightness of the chest on the first day of the working week, Grade 1 - Tightness of the chest and /or difficulty in breathing on each first day only of the working week, Grade 2 - Tightness of the chest and /or difficulty in breathing on the first and other days of the week and Grade 3 - Permanent respiratory disability from reduced ventilatory capacity. Chronic bronchitis was defined as coughing and phlegm for at least three months each year for not less than two successive years. ${ }^{[5]}$ The chronic bronchitic women laborers were distinguished from byssinotics by showing lesser decrease in pulmonary function. ${ }^{[6]}$ Occupational asthma is a chronic respiratory condition characterized by airway inflammation and intermittent episodes of bronchospasm that can be provided by a variety of stimuli at work. ${ }^{[7]}$ It is usually witnessed whenever the subject is exposed to dust and is reversible. The occupational asthmatic workers were differentiated from byssinotics as they do not exhibit Monday morning chest tightness.

\section{Pulmonary function tests (PFT)}

Both the experimental and control group participants were subjected to PFT. Pulmonary function tests included spirometry and chest X-ray analysis.

Assessment of pulmonary function by spirometry is a routine practice in epidemiological surveys in subjects exposed to toxic dusts and air pollutants. ${ }^{[8]}$ Computerized portable vitalograph spirometer was used for conducting pulmonary function tests.

The spirometry included the parametric indices of forced vital capacity (FVC), forced expiratory volume in one second ( $\mathrm{FEV}_{1}$ ), peak expiratory flow (PEF), vital capacity (VC) and $\mathrm{FEV}_{1} / \mathrm{FVC} \%$. The apparatus was calibrated every day and operated within the ambient temperature range of $20-25^{\circ} \mathrm{C}$. The techniques in executing various lung function tests for the present study were based on the operation manual of the instrument with special reference to American Thoracic Society of Standardization of Spirometry. ${ }^{[9]}$ The test was performed with subjects in sitting position with nose clip. The test was repeated three times to obtain appropriate values. The spirometry was carried out on the first day after a weekend holiday at the beginning of the shift and after the shift with a minimum of seven hours exposure to cotton dust. This is because the chest tightness, an important symptom of byssinosis - a cotton dust induced pulmonary disorder, is most commonly manifested after a holiday. ${ }^{[10]}$ For assessing chronic changes, the observed values of FVC, FEV ${ }_{1} \mathrm{PEF}, \mathrm{VC}$ and $\mathrm{FEV}_{1} /$ FVC\% were expressed as a percentage of the predicted values by using the regression equation developed by Vijayan. ${ }^{[1]}$ Reduction of these values below $80 \%$ of predicted value was diagnosed as chronic obstruction in airways.

The pre and post shift differences in FVC, $\mathrm{FEV}_{1}$ and PEF were determined to find out acute changes over shift.

The chest X-ray was also carried out for 104 experimental group and 40 control women to check for any radiographic abnormalities.

\section{Statistical analysis}

Standard normal distribution (two-tailed test) was used to assess the significance of chronic changes with the percentage predicted values of pulmonary function parameters (FVC, FEV $_{1}, \mathrm{PEF}, \mathrm{VC}, \mathrm{FEV}_{1} / \mathrm{FVC}$ ) between exposed and control women. Standard normal distribution was also performed to assess the significance of acute changes by reviewing post shift pulmonary changes of PFT in the exposed women. Multiple correlation and regression analysis were carried out to find the impact of age and duration of exposure to cotton dust on PFT. Prevalence of respiratory impairments observed in these women employed in different sections of the ginning factory were statistically compared using Chisquare test. 


\section{RESULTS}

\section{Physical characteristics}

The ginning factory women laborers recorded mean values of following physical parameters: Age $-51.8 \pm 8.3$ years, weight - $45.1 \pm 8 \mathrm{Kg}$, height $-149 \pm 6.6 \mathrm{cms}$ and blood pressure 117/ $76 \pm 10.7 / 1 \mathrm{mmHg}$. The mean values of weight and height were non-significantly lower than the control women.

\section{Pulmonary morbidity}

The clinical profile of the ginning factory women workers is shown in Table 2.

Among the 104 experimental group participants, 38(37\%) reported symptoms of respiratory symptoms. Among them, $65.7 \%$ were byssinotic symptomatic, $23.7 \%$ were chronic bronchitic symptomatic and $10.53 \%$ were occupational asthmatic symptomatic. The prevalence of asthmatic symptoms was in accordance with earlier reports of asthma among cotton mill textile workers. ${ }^{[12,13]} 44 \%$ of experimental group participants reported other ailments like body aches, headaches, soriasis, defective eye sights, dental problems, hypertension and diabetes. This might be due to aging, poor nutrient diet, low hemoglobin content and heavy work. Nineteen per cent of the experimental group were normal.

Figure 1 illustrates the chronic pulmonary changes in ginning factory women laborers.

There was significant reduction in FVC ( $\mathrm{Z}=2.02$, significant at $5 \%$ level), $\mathrm{FEV}_{1}(\mathrm{Z}=3.45$, significant at $1 \%$ level $), \mathrm{PEF}(\mathrm{Z}=$ 4.76, significant at $1 \%$ level) and $\mathrm{FEV}_{1} / \mathrm{FVC}$ ratio $(\mathrm{Z}=3.36$, significant at $1 \%$ level) in these women when compared to the control women which suggests chronic lung obstruction. Although the VC of these experimental women were different when compared to the control group, the $\mathrm{Z}$ value was not statistically significant.

Four types of maneuver were recognized in ginning factory women laborers using spirometry based on spirometric assessment by Chattopadhyay ${ }^{[14]}$ Normal persons have FVC values above $80.0 \%$ and $\mathrm{FEV}_{1} / \mathrm{FVC}$ above $75 \%$. In restrictive defects, FVC is below $79.99 \%$ and $\mathrm{FEV}_{1} / \mathrm{FVC}$ is above $75.0 \%$.

Table 2: Clinical profile of the ginning factory women laborers

\begin{tabular}{|c|c|c|c|c|c|c|c|c|}
\hline \multirow[t]{3}{*}{ Groups } & \multicolumn{7}{|c|}{ Clinical symptoms } & \multirow{3}{*}{ Normal } \\
\hline & \multicolumn{4}{|c|}{ Byssinosis } & \multirow{2}{*}{$\begin{array}{c}\text { Chronic } \\
\text { bronchitis }\end{array}$} & \multirow[t]{2}{*}{ Asthma } & \multirow{2}{*}{$\begin{array}{c}\text { Other } \\
\text { ailments }\end{array}$} & \\
\hline & $\mathbf{G} 1 / 2$ & G1 & G2 & G3 & & & & \\
\hline $\begin{array}{l}\text { Ginning } \\
\text { factory } \\
\text { women } \\
\text { laborers }\end{array}$ & 11 & 10 & 4 & - & 9 & 4 & 46 & 20 \\
\hline $\begin{array}{l}\text { Control } \\
\text { women }\end{array}$ & - & - & - & - & - & 1 & 12 & 27 \\
\hline
\end{tabular}

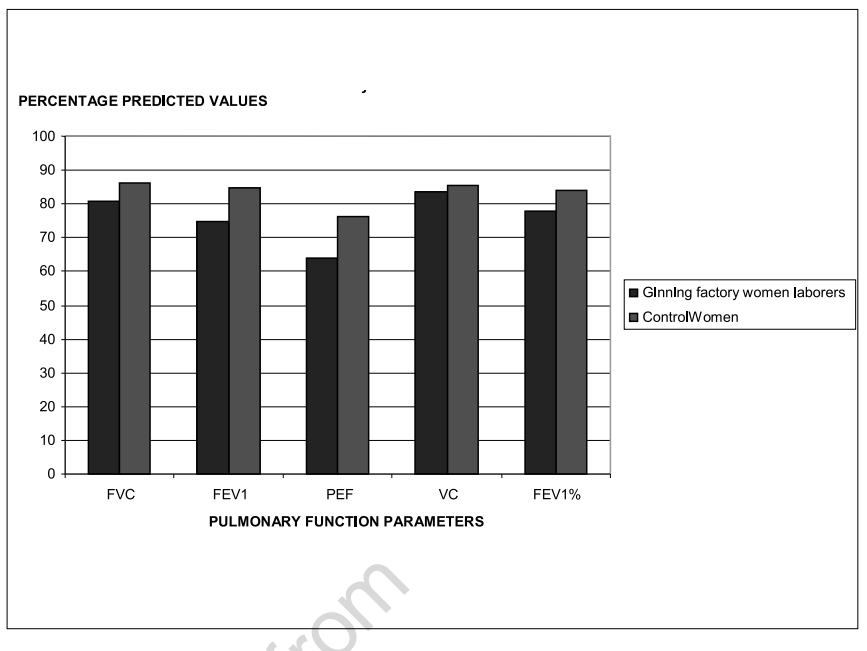

Figure 1: Chronic changes in pulmonary function in ginning

\begin{tabular}{lcccccc} 
Actual values from where [Figure 1] was derived \\
\hline & FVC & FEV & PEF & VC & FEV \\
\hline & 80.74 & 74.56 & 63.84 & 83.69 & 77.59 \\
\hline $\begin{array}{l}\text { Ginning factory women } \\
\text { laborers } \\
\text { Control women }\end{array}$ & 86.34 & 84.81 & 76.27 & 85.30 & 83.73 \\
\hline
\end{tabular}

In obstructive cases $\mathrm{FVC}$ is above $80.0 \%$ but $\mathrm{FEV}_{4} / \mathrm{FVC}$ is below 74.99 mixed obstructive and restrictive defects express both FVC below 79.99 and $\mathrm{FEV}_{1} / \mathrm{FVC}$ below 74.99. In the present study, 64 normal (61.5\%), 35 obstructive (33.7\%), 1 restrictive (0.9\%) and 4 mixed obstructive and restrictive type (3.8\%) conditions were identified in 104 ginning factory women laborers. There was higher prevalence of obstructive conditions $87.5 \%$ (35 out of 40 respiratory abnormal cases) in the ginning factory women laborers. Among the 35 lung obstructive cases 33 showed mild obstruction ( $\mathrm{FEV}_{1} / \mathrm{FVC}$ percentage between $65.00-74.99 \%$ ) and 2 exhibited moderate effect ( $\mathrm{FEV}_{1} / \mathrm{FVC}$ percentage between 50.0-64.99\%). None of the women reported to have severe lung obstruction $\left(\mathrm{FEV}_{1} /\right.$ FVC percentage below 50.0\%). Lung obstruction was more prevalent among byssinotic symptomatics (60.0\%) compared to chronic bronchitic symptomatics (25.7\%) and asthmatics (14.3\%).

Thirty five ginning factory women laborers who showed obstruction were challenged with the bronchodilator salbutamol to explain the nature of reversibility. The obstruction was reversible in $30(85.7 \%)$ ginning factory women laborers and irreversible in $5(14.3 \%)$ women laborers. The irreversibility was more prevalent more among laborers who reported chronic bronchitic symptoms.

$86.5 \%$ of total 104 ginning factory women (90) laborers showed decline in percentage predicted PEF values. Among them $66.7 \%$ (60 out of 90 ) showed mild to moderate change in PEF i.e., percentage predicted PEF values between 60.0 to $80 \%$. 
Remaining 33.3\% (30 out of 90) showed severe (below 60.0\% of predicted value) change in PEF.

Significant acute changes in pulmonary function after the

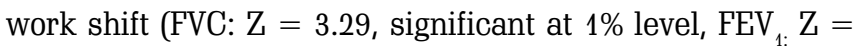
3.74 , significant at $1 \%$ level) were also observed in these women [Figure 2]. There was no statistically significant difference in PEF after the shift $(\mathrm{Z}=1.402)$.

The multiple correlation analysis conducted to determine the combined effects of age and duration of exposure showed five per cent significant correlation of percentage predicted values of pulmonary function indices with age above 50 years and duration of exposure above 20 years (FVC: $\mathrm{r}=0.521_{i} \mathrm{FEV}_{1}: \mathrm{r}$ $=0.2823_{i}$ PEF: $\mathrm{r}=0.3305$ ).

Chest X-rays were taken for all the 104 experimental group participants. Seventy (67.3\%) of them revealed normal pattern; thirty (28.8\%) of them showed mild variation. The remaining four (3.9\%) had severe obstructive lung disease which was

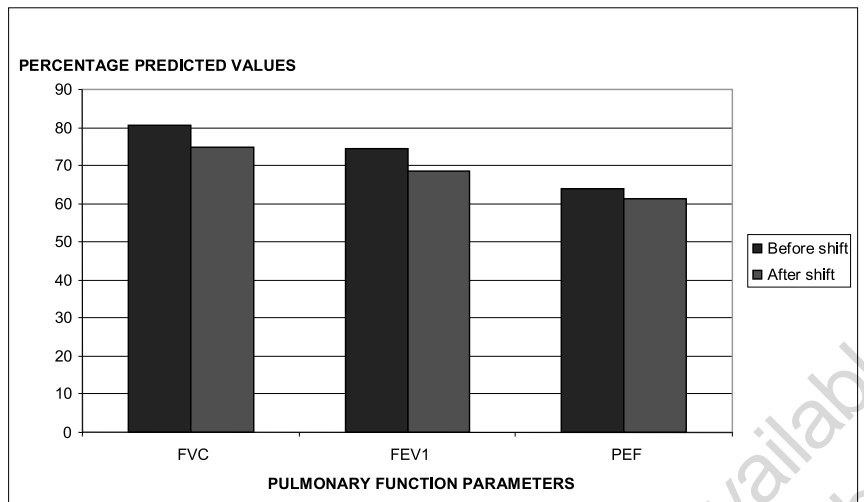

Figure 2: Acute changes in pulmonary function in ginning factory women

Actual values from where Figure 2 was derived

\begin{tabular}{lccc}
\hline & \multicolumn{3}{c}{ Percentage predicted values } \\
\cline { 2 - 4 } & FVC & FEV $_{\mathbf{1}}$ & PEF \\
\hline Before shift & 80.74 & 74.56 & 63.84 \\
After shift & 74.88 & 68.72 & 61.30 \\
\hline
\end{tabular}

clearly indicated in the chest X-rays. The above four women laborers whose X-rays showed severe lung obstruction, also reported to have chronic bronchitic and asthmatic symptoms. As quoted earlier, ${ }^{[3]}$ no specific radiograph abnormalties were observed in women laborers exhibiting byssinotic symptoms.

There were also significantly more number of women laborers with pulmonary impairment in all the sections of the ginning factory [Table 3]. The magnitude of respiratory health hazards in the ginning factory women laborers is shown in Table 4.

\section{DISCUSSION}

The present study concluded the high prevalence pulmonary abnormalities together with respiratory symptoms were high in the selected ginning factory. Although the ginning process is seasonal, both acute and chronic pulmonary abnormalities were visualized, which indicates both short-term and longterm effect of cotton dust on lungs. The prevalence of significantly more number of pulmonary impaired women laborers of all the sections of the ginning factory indicated

Table 4: Magnitude of respiratory health hazards in the ginning factory women laborers

\begin{tabular}{|c|c|c|c|}
\hline \multirow{2}{*}{\multicolumn{2}{|c|}{$\begin{array}{l}\text { Group Group } \\
\text { No. }\end{array}$}} & \multicolumn{2}{|c|}{ Total $(n=104)$} \\
\hline & & Number & Percentage \\
\hline & $\begin{array}{l}\text { X-ray abnormality + respiratory } \\
\text { symptoms + PFT abnormality }\end{array}$ & 13 & 12.5 \\
\hline 2 & $\begin{array}{l}\text { X-ray abnormality + respiratory } \\
\text { symptoms }\end{array}$ & 6 & 5.8 \\
\hline & $\begin{array}{l}\text { X-ray abnormality + PFT } \\
\text { abnormality }\end{array}$ & 15 & 14.4 \\
\hline 4 & Only X-ray abnormality & 0 & 0 \\
\hline 5 & $\begin{array}{l}\text { Respiratory symptoms }+ \text { PFT } \\
\text { abnormality }\end{array}$ & 10 & 9.6 \\
\hline & Only respiratory symptoms & 28 & 26.9 \\
\hline & Only PFT abnormality & 20 & 19.2 \\
\hline 8 & Absolutely normal & 12 & 11.5 \\
\hline
\end{tabular}

Groups 1 to 4 : promotion of health by changing the place of their occupation, dust control in working environment and clinical management as the reversibility of disease in these group is not possible

Groups 5 to 6: promotion of health by usage of respiratory masks, dust control devices should be applied to these groups

Group 8: preventive methods such as usage of respiratory masks should be undertaken, PFT - Pulmonary function tests

Table 3: Distribution of ginning factory women laborers with above and below normal levels of pulmonary functions in different sections of ginning factory

\begin{tabular}{|c|c|c|c|c|c|c|c|}
\hline \multirow[t]{2}{*}{$\begin{array}{l}\text { Sr. } \\
\text { No. }\end{array}$} & \multirow[t]{2}{*}{$\begin{array}{l}\text { Sections of } \\
\text { ginning factory }\end{array}$} & \multicolumn{2}{|c|}{ FVC $\%$ predicted } & \multicolumn{2}{|c|}{ FEV $_{1} \%$ predicted } & \multicolumn{2}{|c|}{ PEF\% predicted } \\
\hline & & $\frac{\text { Above } 80 \%}{\text { (Normal) }}$ & $\frac{\text { Below 80\% }}{\text { (Affected) }}$ & $\frac{\text { Above } 80 \%}{\text { (Normal) }}$ & $\frac{\text { Below 80\% }}{\text { (Affected) }}$ & $\frac{\text { Above } 80 \%}{\text { (Normal) }}$ & $\frac{\text { Below } 80 \%}{\text { (Affected) }}$ \\
\hline 1 & S-1 (56) & 2035.7 & 3664.3 & 610.7 & 5089.3 & 23.6 & 5496.4 \\
\hline 2 & S-2 (38) & 1539.5 & 2360.5 & 1128.9 & 2771.1 & 615.8 & 3284.2 \\
\hline \multirow[t]{2}{*}{3} & S-3 (10) & 880.0 & 220.0 & 550.0 & 550.0 & 110.0 & 990.0 \\
\hline & Total & 4341.3 & 6158.7 & 2221.2 & 8278.8 & 98.7 & 9591.3 \\
\hline $\begin{array}{l}\text { Chi square } \\
\text { value }\end{array}$ & & \multicolumn{2}{|c|}{$6.9484^{*}$} & \multicolumn{2}{|c|}{$10.032^{* *}$} & \multicolumn{2}{|c|}{$4.300^{*}$} \\
\hline
\end{tabular}

${ }^{*}$ Significant at $5 \%$ level, ${ }^{* *}$ Significant at $1 \%$ level, S-1 gin house S-2 gutter S-3 sorting 
the increased cotton dust in the entire premises of the ginning factory.

The following recommendations were suggested for controlling the occupational lung diseases caused by cotton dust in the ginning factory women laborers:

1. Periodic health surveillance to be made essential

2. Proper treatment to be given to the affected women

3. Effective dust-control measures to be adopted

4. Awareness to be created among the proprietors and the workers

\section{ACKNOWLEDGMENT}

We kindly acknowledge all the staff members of department of biochemistry, Avinashilingam Deemed University, Coimbatore, Dr. Mahadevan, Pulmonologist, KG Hospitals, Coimbatore and management of Karunya Deemed University, Coimbatore, for their encouragement and support in this study.

\section{REFERENCES}

1. Gokani VN. Synopsis of thesis - Studies on the microflora of Indian cotton fibres and from textile mill environment with special reference to the role of endo toxin in relation to Byssinosis. National Institute of Occupational Health: Ahmedabad; 1985. p. 1-10.

2. Kaila HL. Occupational health of women in India. Indian J Occup Health 1995;38:1-3.

3. Parkes WR. Byssinosis. In: Occupation Lung disorders. $2^{\text {nd }}$ ed. Butterworths: London; 1982. p. 435-46.

4. Schilling RS, Vigiliani EC, Lammerd B, Valic F, Gilson JC. A report on byssinosis. In XIV International conference on Occupational Health: Madrid; 1963. p. 137.
5. Awad el Karim MA, Osman Y, el Haimi YA. Byssinosis: Environmental and respiratory symptoms among textile workers in Sudan. Int Arch Occup Environ Health 1986;57:101-8.

6. Kamat SR, Kamat GR, Salpekar VY, Lobo E. Distinguishing byssinosis from chronic obstructive pulmonary disease. Results of a prospective five-year study of cotton mill workers in India. Am Rev Res Dis 1981;124:31-40.

7. Ostro BD, Lipsett MJ, Das R. Particulate matter and Asthma. Appl Occup Environ Hyg 1998;13:139.

8. Mohanrao N, Kulkarni PK. Pulmonary function evaluation in subjects occupationally exposed to toxic dust and pollutants. Indian J Ind Med 1995;41:162-6.

9. American Thoracic Society. Statement on standardization of spirometry. Am Rev Res Dis 1987;136:1286-96.

10. Mohanrao N, Kulkarni PK, Sanjed HN. Evaluation of lung function in subjects occupationally exposed to toxic dust and air pollutants. Indian J Occup Environ Med 1998;2:13-7.

11. Vijayan VK, Kuppurao KV, Venkatesan P, Sankaran K, Prabhakar R. Pulmonary function in healthy young adult Indians in Madras. Thorax 1990;45:611-5.

12. Woldeyohannes M, Bergevin Y, Mgeni AY, Theriault G. Respiratory problems among cotton textile workers in ethiopia. Br J Ind Med 1991;48:110-5.

13. Ananthan VS, Anbarasan P, Logamurthy S. Morbidity profile among cotton mill worker in Coimbatore with emphasis on Byssinosis. Indian association of occupational health conference on new trends and development in Occupational Health: 2000. p. 35.

14. Chattopadhyay BP. Pulmonary function tests for evaluation of respiratory impairment in Miners. WHO Training course on Dust Diseases in Miners. Organized by National Institute of Occupational Health: Ahmedabad and Regional Occupational Health Centre: Calcutta; 1999. p. 6-10.

Source of Support: Avinashilingam Deemed University, Dr. Mahadevan, KG Hospitals, Karunya Deemed University, Coimbatore. Conflict of Interest: None declared.

\section{Author Help: Reference checking facility}

The manuscript system (www.journalonweb.com) allows the authors to check and verify the accuracy and style of references. The tool checks the references with PubMed as per a predefined style. Authors are encouraged to use this facility before submitting articles to the journal.

- The style as well as bibliographic elements should be $100 \%$ accurate to get the references verified from the system. A single spelling error or addition of issue number / month of publication will lead to error to verifying the reference.

- Example of a correct style

Sheahan P, O'leary G, Lee G, Fitzgibbon J. Cystic cervical metastases: Incidence and diagnosis using fine needle aspiration biopsy. Otolaryngol Head Neck Surg 2002;127:294-8.

- Only the references from journals indexed in PubMed would be checked.

- Enter each reference in new line, without a serial number.

- Add up to a maximum 15 reference at time.

- If the reference is correct for its bibliographic elements and punctuations, it will be shown as CORRECT and a link to the correct article in PubMed will be given.

- If any of the bibliographic elements are missing, incorrect or extra (such as issue number), it will be shown as INCORRECT and link to possible articles in PubMed will be given. 